\title{
Moving Technology-Enhanced-Learning Forward: Bridging Divides through Leadership
}

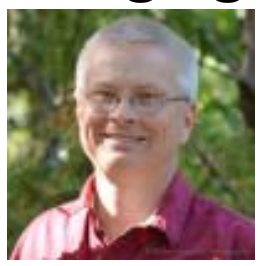

Olle Bälter

KTH Royal Institute of Technology, Sweden

\begin{abstract}
A study of academics and professional staff engaged in the emerging field of Technology Enhanced Learning (TEL) reveal three areas of significant difference in reference to perspectives about TEL. These differences rest on the following individual characteristics: 1) research areas and competencies, 2) academic level, and 3) attitudes towards teaching. While the number of respondents is small, the data set is rich due to a diverse group of respondents. Leadership strategy that rests on appreciative inquiry to draw these perspectives together could begin with implementation of five ways of working collaboratively: acknowledge unique skills different from one's own, understand driving forces from different vantage points, learn enough about other views to show respect, identify common goals and incentives for all, and include people from all relevant groups.
\end{abstract}

Keywords: technology enhanced learning, collaboration, leadership

\section{Introduction}

Technology-Enhanced Learning (TEL) stands at the intersection of technological and pedagogical change as a segment of the e-learning movement. E-learning is viewed as a key to providing wider access to higher education (Daniel, Kanwar, \& Uvalić-Trumbić, 2009), but its quality and reputation are still questioned and will, at least partly, be affected by how campus-based institutions manage to integrate e-learning (Gaskell \& Mills, 2014). As a subset of e-learning, TEL has the potential to be successfully assimilated into engineering education as many staff and students have an interest in technology and are likely to have knowledge of both its benefits and drawbacks. It is therefore of value to consider how faculty, staff, and students interested in TEL are proceeding in campus-based engineering education.

TEL has no universally-accepted definition, but is explicated in the following quote: 
TEL is directed at human creation of knowledge and the human development of competence and its codification in media as heterogeneous as, e.g., courses, books, or instant messages. TEL means supporting human activity needed for knowledge creation and competence development with tools that afford isolated or collaborative endeavors in formal and informal situations (Wild, 2016, p. 5-6).

Many academics seem reluctant to embrace technology (Rientes, Brouwer \& Lygo-Baker, 2013). This is likely related to the need for more evidence-based research that demonstrates teaching with technology has impact on learning outcomes (Menges, 2000; Tadashi Hora, 2012). In addition, teaching skills are not valued and have not been so for more than 100 years (Roxå, 2009). Therefore, introducing new ways of teaching with technology support will be problematic. The working environment within groups interested in TEL can be tension-filled as disparate groups of interest come together to effect change to teaching practice in the intersection of technology and pedagogy.

No one is exempt by background from joining the TEL conversation. However, challenges based on linking cross-disciplinary perspectives exist when attempting to agree on a way forward. In the TEL research area, cross-disciplinary views come together from varied disciplines: pedagogy, computer science, and media technology to name a few. Tedre and Sutinen (2008) write, "It is notoriously difficult to conduct research in the intersection of research traditions without making a mess of it" (p. 154). Some of these difficulties are described by Denzin and Lincoln (2011) and Lincoln, Lynham, and Guba (2011) who identify different positions on the nature of knowledge, knowledge accumulation, quality criteria, values, ethics, and other disciplinary differences (Biglan, 1973a).

These disciplinary differences create significant challenges when attempting to develop common practice for an emerging field like TEL. The literature of epistemological and pedagogical differences across academic disciplines in higher education has a very rich history (Becher \& Trowler, 2001; Biglan, 1973a, 1973b; Shulman, 1987; Mills, Bettis, Miller, \& Nolan, 2005). However, research on this topic in the context of online learning is now receiving empirical attention (Arbaugh, Bangert, \& Cleveland-Innes, 2010; Lam, McNaught, Lee, \& Chan. 2014). Pedagogy, as a social science, is difficult to define and measure or reduce to agreed-upon premises. This is more problematic in some fields than others; according to Dill (2012), there is "greater agreement on ... teaching ... in more paradigmatic fields such as the sciences than in the social sciences and humanities" (p. 3). In addition, faculty role change is required for TEL implementation (Cleveland-Innes \& Gauvreau, 2015); role change that will be defined and implemented in unique ways by discipline.

In order to manage such a transition in perspective and roles in higher education, particular forms of leadership may be required. Findings from this study indicate several strategies that may support the change required to embrace, research, and implement TEL. Employing such strategies as part of the TEL movement implies a particular leadership style; suggestions are included in the conclusion.

\section{Method}

The exploratory case study allows a flexibility of data collection and analysis not offered by other research approaches. This does not suggest a lack of rigor; systematic gathering of empirical data ensures that research evidence is accurate and unbiased. Interview data is gathered from multiple 
respondents, from various disciplines, and in varying positions, to capture perspectives about the barriers and enticers of the progress of TEL in engineering education.

\section{Sampling}

Using a process of purposive sampling, 12 participants are chosen based on their participation in TEL activities; research, conference participation, and testing of technology. All interviews took place in Sweden, but the respondents originate from five different universities in three countries on two continents. Interviewees came from either large research oriented universities or smaller colleges; one-third were women. See background of research participants in Table 1 below.

Table 1

Interviewees by Self-Reported Occupation and Field of Study

\begin{tabular}{|l|l|}
\hline Position & Academic fields \\
\hline 3 Ph.D. students & $\begin{array}{l}\text { Online Learning; Computer Science Didactics; } \\
\text { Distance Learning }\end{array}$ \\
\hline 5 Professors & $\begin{array}{l}\text { Pedagogy (3); Mathematics Didactics; Computer } \\
\text { Science }\end{array}$ \\
\hline 2 Lecturers & Media Technology; Computer Science \\
\hline Pedagogical developer & Online Learning \\
\hline IT support & Communications \\
\hline
\end{tabular}

\section{Data Collection and Analysis Process}

Data collection for this exploratory case study of academic relationships and engineering education consists of text-based records of informal conversations and audio recorded unstructured interviews. This allows for capture of attitudes, the indignation and gaps that are rarely stated in writing. Direct quotes are transcribed from the recordings. Transcripts of the informal conversations are sent to the participants in an email asking whether they are perceived correctly. Participants are invited to alter them to their satisfaction. In some citations, clarifications or context are added within parenthesis.

This analysis process includes open review and full immersion in data to discern individual and collective meanings found in the interview transcripts. We use an inductive coding process with a continuous back-and-forth method of data review. Like the process of identifying emerging themes in a grounded theory protocol (Gibbs, 2008), this process leads to categories of data. These categories are then used to re-analyze the data. From this, a structure emerges such that an axial coding process is reemployed. In the final pass, categories of data with coding schemes are then shaped and reemployed in a final, closed coding process.

\section{Results}

The participants described the TEL field from their point of view. The statements made by the participants were categorized into three themes. The themes regard divides or gaps and 
commonalities between academic subjects and competences, academic levels, and views on the importance of teaching.

\section{Theme I: Divides Between Involved Academic Subjects and Competences}

Many of the participants described a divide between different academic subjects. This may be a natural part of necessary separation between academic subjects, but the separation of pedagogy is very pronounced: "Many mathematicians are doubtful towards all pedagogical research. ... In many mathematicians' eyes, I am not a mathematician, despite that I have defended my thesis in mathematics education" ( $\mathrm{P}_{4}$ ). This divide between pedagogues and others is not limited to mathematicians, as it included politicians: "Our leading politicians have the opinion that all educational research is fuzzy" (P6).

Findings suggest that some experts in pedagogy, or pedagogues, reached outside their competence area when they are doing research in engineering education. One of the professors in pedagogy was well aware that his subject was not always appreciated in engineering education, as identified in this quote: "Pedagogy contains too little information per time unit to fit engineers." (Roxå, 2009, p. 2). The same pedagogy professor mentioned that, even within his field, tensions existed between theoretical researchers and practitioners:

I perceive this as a tension between this research field, that has not always been useful in practice, and the pedagogical development that just attempt to be useful. This tension was notable also for others who had been in close proximity of the research area: 'The two camps are pedagogues and didactics.'

Similarly, findings suggest a divide between pedagogical researchers and pedagogical developers; the latter were accused of simplifying too much: "(pedagogical developers) cannot learn one method and state this is the Method, with a capital M, that will solve all my pedagogical problems."

This lack of understanding of the differences between pedagogical research and practice can influence the surroundings negatively, as it was expected that all pedagogues also should be scholars in practical didactics. Outside the field of pedagogy, not all can distinguish between the pedagogical researchers and the pedagogical developers: "This group (pedagogical researchers) is very peripheral to me. I do not see any difference between them (pedagogical researchers) and (pedagogical) developers.”

Findings suggest generalized conclusions were being made about this new pedagogy. One participant identified that problems with one pedagogical developer may paint all pedagogical developers with the same brush:

Teachers must feel that the pedagogical developer supports them if it should work. If they feel that they will be evaluated and slashed by the pedagogical developer, (ironically) maybe they will not ask for their assistance to the same extent.

It was not only this risk of being evaluated that deterred teachers from contacting pedagogical developers, but also that the developers would overstretch their field of competence: "The educational (pedagogical) developers have been a little too pushy. They have opinions not only about the tool, but also how it should be used. They have not been so receptive at all times." 


\section{Theme II: Divide Between Involved Academic Levels}

The pedagogues above were not alone in this criticism from the other academics. Technology professionals were well aware of academics criticizing them for being unresponsive, slow, and expensive:

It does not matter in what order you prioritize not to do these things! and perhaps it seemed like that from his perspective, but we had gladly made them (the proposed changes), all of them, as soon as tomorrow, but even if the management now think this (e-learning) is important, they have not provided very much resources.

This mistrust was mutual. Despite the academics' often deep knowledge on technical issues at a technical university, there was not much understanding for the difference between experimental settings in the academics' world and running a system in a real, live environment on the IT support side:

People here are working with the web, using the Web as a tool. So there are an awful lot of opinions about what we (IT support) should do. And they also know that it is very easy to do this, because they have built their own website or whatever it is, but the problem is when you scale it up in an organization where this must work flawlessly for 4,800 persons 24/7. But it's an area where it is easy to have opinions.

Many participants described a divide between "real" academics, i.e. those with PhDs who were employed as professors, and others working at their universities:

Some really have a special competence. They have 10-15 years of experience from these things and have built up an expertise precisely about this area. And there are not that many who have those skills. But they get no credit for it in this academic system because they are employed as administrative staff or lecturers. And then it becomes a problem because there is a formal problem of legitimacy: well you're not a Ph.D. in this!

\section{Theme III: Divide in Teaching Attitudes}

In addition to the divides between academic subjects and academic levels, findings identify a divide in attitudes towards teaching that cuts through subjects and academic levels: "I find some in the lecturer group and some in the professor group who think that education is important. And (there are some) where I cannot find it."

It may be that the origins of this attitude came from professors who focused on their research and avoided teaching altogether as suggested in this quote:

There is a direct conflict between these two groups (lecturers and professors). Some researchers (professors) have teaching obligations, but they want to teach something close to their area of research. It's just that their field is very narrow and very peripheral in work life. Maybe there's room for one or two positions in the country outside the university. There is a direct conflict. They want to teach what they are doing research about and not basic courses that are too general. To maintain their own skills, I suppose, and perhaps to be able to recruit talented graduate students as well. 
Examples of uninterested teachers were relayed as offering poor quality in teaching and grading:

The danger of having researchers who do not want to teach is severe. The classes become really bad and everyone stops going. One teaching assistant becomes super popular. I taught with a person who did not want to teach and then I had a lecture hall seating 45 with 90 students instead. And there was a researcher who did not want to (teach) .... And when it came to grading, in the end, we assistants did everything and he basically just signed it. ... Then there was this other professor who did not want to grade their finals and wrote pass on everyone to get it over with.

Findings suggest a conflict between wanting to be a successful researcher, which was what was rewarded, and the teaching obligations they were hired to fulfill:

Teaching is seen a bit like punishment here, and the school sees its prestige as 'look we have PhDs here.' But the PhDs would rather do other things and teaching must continue. (The professors) usually do not have a PhD in Education, they are PhDs in something else that they're doing, or have another area of interest they want to engage in. So the career is not promoted much by being good at teaching.

When research was the only thing rewarded, the lack of incentives for improving as a teacher lead to less improvement:

The present system does not provide sufficient incentives for the individual to develop outstanding education, in contrast to development as a researcher ... If you get a paper published, you will get a cake or a congratulatory email from the management, but as a lecturer or technical support there is no way to get a cake when you do a great job.

This lack of appreciation for teaching was not only felt among disgruntled lecturers and PhD students, it was noted by the professors as well: "The only time that you feel you are getting any appreciation is when you get a grant or an article accepted."

There were also some positive suggestions on how to improve the situation. Setting common goals for teaching/education that were more than just giving a course could be a small step in the right direction: "What I perceive as a problem is that we do not strive toward the same goals."

Another proposal was to admit that we are all different and these differences should be acknowledged:

Teaching is a form of expression as well, so it's not that one method is best for everyone and it's not that one tool is best for everyone. And it is not even certain that you should use a tool for a particular thing is best for all people. It depends a bit on how they work in general and what their relationships with their students are.

\section{Discussion}

This paper describes an exploratory case study of the field of Technology-Enhanced Learning. The selection of interviewees is purposefully designed to capture the voice of multiple occupational 
categories involved in TEL. Most interesting about the data from the exploratory case about the integration of TEL in university teaching is that the discussion landed more on infrastructure issues than the technology itself.

The three divides identified by are identified by the data in this study:

1. Divides between involved academic subjects and the related competences.

2. Divide between involved occupational and academic levels.

3. Divide in attitudes toward teaching.

For the TEL community, as in any other cross-disciplinary community, these divides will all impede the progress in the area, but the last divide is the most devastating of all. When university teachers do not consider teaching important, they will have no or little interest in TEL research results. This obstructs dissemination of TEL research results. This is not unique to TEL initiatives, but the issues around teaching and its place in university structure is a significant issue in higher education reform (Cleveland-Innes \& Gauvreau, 2015).

While our original orientation to the study focused on the issue of integrating TEL into university teaching, the following summary comments relate broadly to higher education reform (Duderstat, 2009) and the multiple challenges required when making any single change like improving teaching. Our first key insight is that there are noted divides, as described above, which make it difficult to move groups forward with decisive action toward change. Leadership strategy becomes a key response; first to bridge any existing divides and then creating a shared vision and agree upon action plans. In addition, we note other challenges identified by the findings that require remediation.

Teaching and learning knowledge rests on disciplinary characteristics, characteristics which vary significantly across disciplines (Biglan, 1973b). For example, respondents in this study suggest pedagogical researchers are too theoretical and have no connection with real teaching or didactics. As a counter to this, pedagogical researchers suggest those trained in other subjects are too focused on experimental methods alone and do not know anything about the science of teaching and learning.

Excellent teaching is not rewarded nearly as much as mediocre research. Lecturers are trapped in an academic hierarchy where they do not have a PhD, are not supported to do research, and are expected to teach well in a system that does not provide promotion opportunities on the strength of good teaching alone.

Staff who are in non-academic positions have a significant contribution to make in integrating TEL and promoting good teaching. Pedagogical developers have a task to promote pedagogical and didactical knowledge to the teachers, but teachers who are academics do not appreciate being told how they should be teaching, particularly by someone who is not an academic or does not have a Ph.D. The IT staff have demands not always visible to the teachers: staying on budget, keeping things simple for non-technical staff and faculty, and providing technical troubleshooting and maintenance. This results in them being perceived as slow, unresponsive, and expensive. In science programs, the widespread technical knowledge can serve to hinder TEL implementation, as everyone has their own opinion on what and how it should be done. At the same time, it might be among these experimenting teachers the next big thing in TEL evolves. 
This described lack of collaboration on university campuses is not new or unique to TEL implementation. Disciplinary differences identified as group identity (Dill, 2012) may explain the need to remain within a disciplinary group and not engage with outsiders. Respondents describe little about their own group identity, but have much to say about those in a group outside their own.

While the three themes paint a picture of conflict, findings identify some understanding across groups of the perspective of others. The lecturers exhibit some understanding why the professors prioritize the way they do, based in the imposed reward structure. Technology professionals, or IT support staff, are aware that the technical demands on teachers are unnecessarily high; "In a classroom situation, teachers are not expected to change the light bulbs. Why do we expect that in an online environment?" The pedagogical researchers understand the pressure on pedagogical developers to simplify things, and teachers do understand that IT systems are not perfect for everyone. And, with some reservation, findings indicate that working together may be one way to increase this understanding.

We suggest that bridging these divides so that more collaborative work can occur is a possible remedy; to employ this remedy requires leadership. Many leadership theories are available to guide such action (Avolio, Walumbwa, \& Weber, 2009); however, the need for appreciation of the views of others suggests that Appreciative Leadership (Orr \& Cleveland-Innes, 2015) may be of value in the implementation of TEL. According to Orr and Cleveland-Innes (2015):

The role of an appreciative leader is to be a catalyst of change and to look for and nurture the best in others (Whitney, Trosten-Bloom, \& Rader, 2010; Cooperrider \& Whitney, 2005). An Appreciative Leader is a strength-based leader. Leaders are considered to be role models of appreciative inquiry in their relationships with others and participate along with other staff and colleagues in the inquiry process. In a sense, the leader is less important than the questions she or he asks, the discourse these questions create, and the ongoing quest of seeing the positive potential in both the staff and organization. (p. 6)

This type of leadership could support the implementation of five new ways of working collaboratively: acknowledge unique skills different from one's own, understand driving forces from different vantage points, learn enough about other views to show respect, identify common goals and incentives for all and include people from all relevant groups.

\section{Conclusions}

We conclude that leadership which fosters cross-disciplinary cooperation between faculty who are subject-matter experts, IT professionals, and pedagogical developers is critical to successful TEL implementation; implementation that will improve the higher education teaching and learning experience for an increasingly diverse student body.

Interviewees in this study come from both large universities and smaller colleges on two continents; however, the respondents are not randomly chosen, in sufficient numbers, or diverse enough to claim representation for the TEL community as a whole. There are likely universities and colleges that have made more progress, where the move toward integrated, collaborative, cross-disciplinarity is achieved and groups are striving towards the same goals. For the other universities and colleges, this study 
sheds light on reasons why technology-enhanced learning has not yet reached its full potential, and what may be done in response.

The respondents in this study from Technology Enhanced Learning paint a picture of a field divided into three dimensions: 1) between academic subjects and competences, 2) between academic levels, and 3) in attitudes toward teaching.

The last divide is of significant value within the TEL research field, but it can be expected that nonacademics who devote their professional career to learning support are actually interested in teaching and find it important. However, the low priority placed on good teaching by faculty, represented in this study by phrases like "teaching obligations" and "teaching burden," creates a notable divide and a significant barrier. Even before the imposition of new technology, both excellent teaching and excellent research records are difficult to achieve. Fairweather's (2002) research suggests that new ways of teaching will make it more difficult for faculty to be exemplars of research and teaching. This is untenable given the current demands for higher education change, demands which, in relation to improving instruction and using the available technology, can be addressed by TEL where "traditional teaching methods become questioned as expectations change" (Rienties, Brouwer, \& Lygo-Baker, 2013, p. 123).

Research results from the TEL area, or any other educational area, have little hope of migrating to faculty who are uninterested in teaching. Also, in university environments where teaching is perceived as a burden, the quality will not be high, regardless of how ingenious the technical support devices become. Leadership that bridges this divide and supports the valuing of all that will reform higher education, including TEL, is now required.

Future research needs to continue this exploration. Research that describes existing leadership where TEL is and isn't being implemented, will test our suggestions. A larger sample of higher education faculty and staff from multiple campuses involved in some way with TEL as it currently exists on campuses would add to these preliminary conclusions. Lewin's Force Field Analysis (Rabak \& Cleveland-Innes, 2006) could be employed to systematically identify enticers and detractors that exist in the higher education context for TEL implementation.

\section{References}

Arbaugh, J. B., Bangert, A., \& Cleveland-Innes, M. (2010). Subject matter effects and the community of inquiry (CoI) framework: An exploratory study. The Internet and Higher Education, 13(1), 37-44.

Avolio, B., Walumbwa, F., \& Weber, T.J. (2009). Leadership: Current theories, research, and future directions. Annual Review of Psychology, 6o(2009), 421-449.

Becher, T., \& Trowler, P. (2001). Academic tribes and territories: Intellectual enquiry and the culture of disciplines. UK: McGraw-Hill Education. 
Biglan, A. (1973a). The characteristics of subject matter in different academic areas. Journal of Applied Psychology, 57, 195-203.

Biglan, A. (1973b). Relationships between subject matter characteristics and the structure and output of university departments. Journal of Applied Psychology, 57, 204-213.

Cleveland-Innes, M., \& Gauvreau, S. (2015). Faculty role change: Adjustment to the influence of online teaching and learning. European Journal of Open, Distance and eLearning, EDEN Special Issue. Retrieved from http://www.eurodl.org/materials/special/2015/Cleveland-Innes Gauvreau.htm

Cooperrider, D., \& Whitney, D. D. (2005). Appreciative inquiry: A positive revolution in change. New York, N.Y.: Berrett-Koehler Publishers.

Daniel, J., Kanwar, A., \& Uvalić-Trumbić, S. (2009). Breaking higher education's iron triangle: Access, cost, and quality. Change: The Magazine of Higher Learning, 41(2), 30-35.

Denzin, N.K., \& Lincoln, Y.S. (2011). Introduction: The discipline and practice of qualitative research. In N.K. Denzin, \& Y.S. Lincoln (Eds.), The Sage handbook of qualitative research, (4th ed., pp. 1-20). London: Sage Publications.

Dill, D. (2012). The management of academic culture revisited: Integrating universities in an entrepreneurial age. In B. Stensaker, J. Välimaa, \& C. Sarrico (Eds.), Managing reform in universities: The dynamics of culture, identity and organizational change (p. 222237). Basingstoke: Palgrave Macmillan.

Duderstadt, J. J. (2009). A university for the 21st century. Ann Arbor, Michigan: University of Michigan Press.

Fairweather, J. S. (2002). The mythologies of faculty productivity: Implications for institutional policy and decision making. The Journal of Higher Education, 73(1). Retrieved from http://202.198.141.77/upload/soft/oooo/73.1fairweathero2\%5B1\%5D.pdf

Gaskell, A., \& Mills, R. (2014). The quality and reputation of open, distance and e-learning: What are the challenges, Open Learning: The Journal of Open, Distance and e-Learning, 29(3), 190-205.

Gibbs, G. R. (2008). Analysing qualitative data. London: Sage Publications.

Lam, P., McNaught, C., Lee, J., \& Chan, M. (2014). Disciplinary difference in students' use of technology: Experience in using eLearning strategies and perceptions towards eLearning. Computers and Education, 73, 111-120.

Lincoln, Y. S., Lynham, S. A., \& Guba, E. G. (2011). Paradigmatic controversies, contradictions, and emerging confluences, revisited. In N.K. Denzin, \& Y.S. Lincoln (Eds.), The Sage handbook of qualitative research ( ${ }^{\text {th }}$ ed., pp. 97-128). Thousand Oaks, CA: Sage Publications. 
Menges, R. (2000). Shortcomings of research on evaluating and improving teaching in higher education. New Directions for Teaching and Learning, 20Oo(83), 5-11.

Mills, M., Bettis, P., Miller, J. W., \& Nolan, R. (2005). Experiences of academic unit reorganization: Organizational identity and identification in organizational change. The Review of Higher Education 28(4), 597-619.

Orr, T., \& Cleveland-Innes, M. (2015). Appreciative leadership: Supporting education innovation. The International Review of Research in Open and Distributed Learning, 16(4).

Rabak, L., \& Cleveland-Innes, M. (2006). Acceptance and resistance to corporate elearning: A case from the retail sector. Canadian Journal of Distance Education, 21(2), 115-134.

Rienties, B., Brouwer, N., \& Lygo-Baker, S. (2013). The effects of online professional development on higher education teachers' beliefs and intentions towards learning facilitation and technology. Teaching and Teacher Education, 29, 122-131.

Roxå, T. (2009, December). Vägar till förändring av teknisk utbildning - att tina upp pedagogiken. Den 2:a Utvecklingskonferensen för Sveriges ingenjörsutbildningar [Roads to change of technical education - to thaw the pedagogy. $2^{\text {nd }}$ development conference for Swedish engineering education] LTH. Retrieved from http://www.konferenslund.se/pp/W Roxa.pdf

Shulman, L. S. (1987). Knowledge and teaching: Foundations of the new reform. Harvard Educational Review, 57(1), 1-22.

Tadashi Hora, M. (2012). Organizational factors and instructional decision-making: A cognitive perspective. The Review of Higher Education, 35(2), 207-235.

Tedre M., \& Sutinen E. (2008). Three traditions of computing: What educators should know. Computer Science Education, 18(3), 153-170.

Wild, F. (2016). Learning analytics in R with SNA, LSA, and MPIA. Berlin: Springer.

Whitney, D., Trosten-Bloom, A., \& Rader, K. (2010). Leading positive performance: A conversation about appreciative leadership. Performance Improvement, 49(3), 5. 